\title{
Color Stability of New Composite Restorative Materials Under Accelerated Aging
}

\author{
J. M. POWERS, P. L. FAN, and C. N. RAPTIS \\ School of Dentistry, The University of Michigan, Ann Arbor, Michigan 48109
}

The color stability of seven microfilled and conventional composites under conditions of accelerated aging was evaluated by reflection spectrophotometry. During early aging the composites generally became darker, more chromatic, and more opaque. The in vitro color stability of the microfilled composites was better and less influenced $b y$ erosion than the conventional composites.

J Dent Res 59(12):2071-2074, December 1980

Introduction.

The color stability of seven conventional composite restorative materials, an unfilled acrylic resin, and three glazes under conditions of accelerated aging was evaluated in an earlier study by reflection spectrophotometry. ${ }^{1}$ After aging for $300 \mathrm{~h}$, the composite materials had lower values of luminous reflectance and higher values of excitation purity, dominant wavelength, and contrast ratio, compared to values of baseline. In a 24-month clinical study of color stability of class 4 composite restorations, Dennison and associates ${ }^{2}$ demonstrated that changes in color observed clinically correlated well with changes reported in the aforementioned in vitro study.

Recently new composite restorative materials with novel initiators, resin matrices, and fillers have become available. The purpose of this study was to evaluate the in vitro color stability of several new composites.

Received for publication February 4, 1980 Accepted for publication February 21, 1980

This investigation was presented at the annual meeting of the American Association for Dental Research in Los Angeles, CA, March, 1980.

This investigation was supported in part by Service Award DE-07057 from the National Institutes of Health, Bethesda, MD 20205.

The cooperation of $3 \mathrm{M} \mathrm{Co.,} \mathrm{Imperial} \mathrm{Chemical}$ Industries, Ltd., Phasealloy, Inc., S. S. White Co., and Vivadent (USA), Inc. for supplying commercial products used in this study is acknowledged.

\section{Materials and methods.}

The color of seven commercial composite materials, including three conventional composites (C, FF, and $P R$ ) and four microfilled composites (I, PF, SF, and SI), was evaluated under conditions of accelerated aging. The code, shade, batch number, and manufacturer are listed in Table 1 for each material studied.

Three disks $(36 \mathrm{~mm}$ in diameter and 1.3 $\mathrm{mm}$ in thickness) were prepared for each material by polymerization in a metal die. The disks were placed in an oven at $37^{\circ} \mathrm{C}$ within $90 \mathrm{sec}$ after initiating the mix and were stored for $24 \mathrm{~h}$ before making the baseline evaluation. Disks of the material accelerated by visible light (FF) were polymerized in the same die by exposing the open side through a thin glass plate to a tungsten-halogen light $\#$ with a blue filter. The arithmetic average roughness of a sample as measured from profile tracings ${ }^{\dagger}$ was 2.5 $\mu \mathrm{m}$.

The disks were exposed to conditions of accelerated aging for a total of $900 \mathrm{~h}$ in a weathering chamber at $43^{\circ} \mathrm{C}$ and $90 \%$ relative humidity. One surface of each sample was subjected continuously to the radiation of a 2500 watt ultraviolet (uv) light source $\S$ filtered by borosilicate glass and to an intermittent water spray for 18 min every two $h$. The intensity of the uv radiation was measured with a uv meter ${ }^{\infty}$ to be about $11.2 \mathrm{mWatts} / \mathrm{cm}^{2}$ at the specimen position. Color evaluations were made 48104

\#Riluma bulb, Quarry, Inc., Ann Arbor, MI

†Surfanalyzer 150, Gould, Inc., Instrument Systems Division, Cleveland, OH 44114

$\$$ Weather-Ometer 25WR, Atlas Electric Devices Co., Chicago, IL 60613

\$12-2881 Xenon Burner, Atlas Electric Devices Co., Chicago, IL 60613

${ }^{\infty}$ Model J-221, Ultraviolet Products, Inc., San Gabriel, CA 91778 
TABLE 1

CODE, NAME, BATCH NUMBER, AND MANUFACTURER OF PRODUCTS TESTED

\begin{tabular}{|c|c|c|c|c|}
\hline Code & $\begin{array}{l}\text { Product Name } \\
\text { (Shade) }\end{array}$ & & $\begin{array}{l}\text { atch } \\
\text { mber }\end{array}$ & Manufacturer \\
\hline \multicolumn{5}{|c|}{ Conventional Composites: } \\
\hline $\mathrm{C}$ & $\begin{array}{l}\text { Concise } \\
\text { (Universal) }\end{array}$ & $\begin{array}{l}\text { Paste A } \\
\text { Paste B }\end{array}$ & $\begin{array}{l}-8 Y 21 \\
-8 Y 21\end{array}$ & $\begin{array}{l}3 \text { M Company } \\
\text { St. Paul, MN } 55101\end{array}$ \\
\hline FF & $\begin{array}{l}\text { Fotofil } \\
\text { (White) }\end{array}$ & Paste & $\begin{array}{l}\text { F3762, ADM, } \\
44092 / 76\end{array}$ & $\begin{array}{l}\text { Imperial Chemical Industries, Ltd. } \\
\text { Macclesfield Cheshire, } \\
\text { Great Britain }\end{array}$ \\
\hline PR & $\begin{array}{l}\text { Profile } \\
\text { (Base Shade 55) }\end{array}$ & $\begin{array}{l}\text { Base } \\
\text { Catalyst }\end{array}$ & $\begin{array}{l}-47812 \\
-\quad 37901\end{array}$ & $\begin{array}{l}\text { S. S. White Company, } \\
\text { Division of Pennwalt Corp. } \\
\text { Philadelphia, PA } 19102\end{array}$ \\
\hline \multicolumn{5}{|c|}{ Microfilled Composites: } \\
\hline $\mathbf{I}$ & $\begin{array}{l}\text { Isopast } \\
\text { (Shade 22) }\end{array}$ & $\begin{array}{l}\text { Base } \\
\text { Catalyst }\end{array}$ & $\begin{array}{r}-721078 \\
-\quad 630179\end{array}$ & $\begin{array}{l}\text { Vivadent (USA), Inc. } \\
\text { Buffalo, NY } 14214\end{array}$ \\
\hline $\mathbf{P F}$ & $\begin{array}{l}\text { Phaseafill } \\
\text { (Shade GO) }\end{array}$ & $\begin{array}{l}\text { Base } \\
\text { Catalyst }\end{array}$ & $\begin{array}{l}-026 \\
-\quad 044\end{array}$ & $\begin{array}{l}\text { Phasealloy, Inc. } \\
\text { El Cajon, CA } 92021\end{array}$ \\
\hline $\mathrm{SF}$ & $\begin{array}{l}\text { Superfíl } \\
\text { (Universal) }\end{array}$ & $\begin{array}{l}\text { Universal } \\
\text { Catalyst }\end{array}$ & $\begin{array}{l}-80338 \\
-80329\end{array}$ & $\begin{array}{l}\text { Harry J. Bosworth Co. } \\
\text { Skokie, IL } 60076\end{array}$ \\
\hline SI & $\begin{array}{l}\text { Silar } \\
\text { (Universal) }\end{array}$ & $\begin{array}{l}\text { Universal } \\
\text { Catalyst }\end{array}$ & $\begin{array}{lr}-\quad \text { MPP-501 } \\
-\quad 49013-47\end{array}$ & $3 \mathrm{M}$ Company \\
\hline
\end{tabular}

before weathering (baseline) and after exposure of 300,600 , and $900 \mathrm{~h}$.

Curves of percent reflectance versus wavelength $(\lambda)$ were obtained for each sample between 405 and $700 \mathrm{~nm}$ with a double-beam ultraviolet-visible spectrophotometer and integrating sphere. ${ }^{* *}$ Luminous reflectance (Y), dominant wavelength (DW), and excitation purity (EP) were obtained for each sample backed by both a black" and a white standard.*3 An estimate of the opacity of each material was obtained by calculation of the contrast ratio (CR), Y black standard/Y white standard. 4

The spectrophotometric parameters $(Y$, DW, EP, and CR) were studied by analysis of variance 5 to determine the effects of aging. Scheffe intervals ${ }^{6}$ at the $95 \%$ level of confidence were calculated for comparisons among means.

I ACTA C III UV-Visible Spectrophotometer, Beckman Instruments, Inc., Irvine, CA 92664

**ASPH-U Integrating Sphere, Beckman Instruments, Inc., Irvine, CA 92664

"Part No. 375287, Beckman Instruments, Inc., Irvine, CA 92664

*Part No. 375285, Beckman Instruments, Inc., Irvine, CA 92664

\section{Results.}

Mean values and standard deviations of luminous reflectance $(\mathrm{Y})$, dominant wavelength (DW), excitation purity (EP), and contrast ratio (CR) are listed in Tables 2 and 3 for the conventional and microfilled composites, respectively, at baseline. Changes in these parameters at each evaluation period are listed in the same tables. These changes were computed by subtracting the value of the parameter at 300,600 , and $900 \mathrm{~h}$ from the baseline value. Values of Scheffe intervals computed from analyses of variance were $\mathrm{Y}, 0.8$; DW, $0.61 \mathrm{~nm}$; EP, 0.011 ; and $\mathrm{CR}, 0.013$ for comparisons among times at the $95 \%$ level of confidence.

Values of luminous reflectance (Y) decreased between 0 and $300 \mathrm{~h}$ for all products tested. Changes at $300 \mathrm{~h}$ ranged from $-0.7 \%$ for $\mathrm{PF}$ to $-10.6 \%$ for $\mathrm{C}$. Between 300 and $900 \mathrm{~h}$, luminous reflectance increased as much as $11.5 \%$ compared to 300 -hour values for the conventional composites (C, FF, and PR, Table 2), but continued to decrease by as much as $6.2 \%$ for the microfilled composites (I, PF, SI, and SF, Table 3).

Values of dominant wavelength (DW) between 0 and $900 \mathrm{~h}$ increased for the 
TABLE 2

SPECTROPHOTOMETRIC COLOR DATA AT BASELINE AND CHANGES IN COLOR AFTER AGING FOR CONVENTIONAL COMPOSITES

\begin{tabular}{llccccc}
\hline & & & & \multicolumn{3}{c}{ Change in Parameter Compared to Baseline } \\
\cline { 5 - 6 } Code & Property & Baseline Value & $300 \mathrm{~h}$ & $600 \mathrm{~h}$ & $900 \mathrm{~h}$ \\
\hline $\mathrm{C}$ & $\mathrm{Y}$ & $65.9(0.3)^{*}$ & $-7.0 \dagger$ & -1.2 & -0.2 \\
& DW, nm & $579.07(0.05)$ & 0.22 & 1.34 & 1.53 \\
& EP & $0.327(0.004)$ & 0.058 & -0.089 & -0.123 \\
& CR & $0.644(0.012)$ & 0.041 & 0.149 & 0.170 \\
FF & Y & $78.1(1.5)$ & -7.3 & -2.7 & -1.5 \\
& DW, nm & $573.72(0.11)$ & 2.63 & 3.19 & 3.67 \\
& EP & $0.232(0.008)$ & 0.094 & -0.045 & -0.087 \\
& CR & $0.559(0.029)$ & 0.138 & 0.229 & 0.263 \\
PR & Y & $65.4(1.5)$ & -4.3 & -5.5 & -3.2 \\
& DW, nm & $577.7(2.3)$ & 1.22 & 1.36 & 3.69 \\
& EP & $0.298(0.011)$ & 0.010 & 0.016 & -0.121 \\
& CR & $0.624(0.012)$ & 0.015 & 0.050 & 0.198 \\
\hline
\end{tabular}

* Mean of three replications with standard deviation in parentheses.

$\dagger$ Change equals the value at the specific times minus the value at baseline.

TABLE 3

SPECTROPHOTOMETRIC COLOR DATA AT BASELINE AND CHANGES IN COLOR AFTER AGING FOR MICROFILLED COMPOSITES

\begin{tabular}{llccccc}
\hline & & & \multicolumn{3}{c}{ Change in Parameter Compared to Baseline } \\
Code & Property & Baseline Value & $300 \mathrm{~h}$ & $600 \mathrm{~h}$ & $900 \mathrm{~h}$ \\
\hline I & Y & $63.7(0.4)^{*}$ & -3.17 & -3.8 & -5.2 \\
& DW, nm & $579.08(0.02)$ & 0.18 & 0.29 & 0.25 \\
& EP & $0.344(0.005)$ & -0.015 & -0.017 & -0.025 \\
& CR & $0.647(0.008)$ & 0.009 & 0.018 & 0.020 \\
PF & Y & $58.0(1.2)$ & -0.4 & -1.1 & -4.0 \\
& DW, nm & $578.73(0.22)$ & -0.51 & -0.63 & -0.81 \\
& EP & $0.35(0.002)$ & 0.001 & 0.012 & 0.014 \\
& CR & $0.683(0.020)$ & -0.003 & -0.002 & 0.004 \\
SF & Y & $63.0(0.2)$ & -2.4 & -3.7 & -5.1 \\
& DW, nm & $578.30(0.08)$ & -0.08 & 0.17 & 0.11 \\
& EP & $0.321(0.004)$ & 0.003 & 0.025 & 0.026 \\
& CR & $0.621(0.018)$ & -0.003 & 0.020 & 0.035 \\
SI & Y & $64.6(0.1)$ & -3.8 & -5.0 & -4.6 \\
& DW, nm & $578.71(0.04)$ & -0.05 & 0.16 & 0.12 \\
& EP & $0.326(0.005)$ & 0.016 & 0.042 & 0.051 \\
& CR & $0.624(0.002)$ & -0.004 & 0.007 & 0.015
\end{tabular}

* Mean of three replications with standard deviation in parentheses.

†Change equals the value at the specific time minus the value at baseline.

conventional composites ( $\mathrm{C}, \mathrm{FF}$, and $\mathrm{PR}$ ), decreased for $\mathrm{PF}$, and did not change significantly for I, SI, and SF. The dominant wavelength of $\mathrm{FF}$ and $\mathrm{PR}$ changed much more than that of either $\mathrm{C}$ or $\mathrm{PF}$.
After $300 \mathrm{~h}$ of aging, the excitation purity (EP) of C, FF, and SI increased. Values of EP for PR, PF, and SF did not change significantly, whereas the value of EP of I decreased. Between 300 and $900 \mathrm{~h}$, 
the EP of the conventional composites (C, FF, and PR) decreased by as much as $41 \%$, compared to baseline. The EP of I decreased about $7 \%$, whereas those of PF, SI, and SF increased by as much as $16 \%$.

The contrast ratio of all the composites increased after $900 \mathrm{~h}$ of aging, except that of $\mathrm{PF}$, which did not change. Values of CR of the conventional composites changed between 26 and $47 \%$, whereas those of the microfilled composites changed between 2 and $6 \%$ (except PF).

\section{Discussion.}

Color changes in composite restorations in vivo may be caused by the formation of colored degradation products, by changes in surface morphology because of wear, and by extrinsic staining. Accelerated aging in a weathering chamber appears to model the first two of these mechanisms.

During early aging, both the conventional and the microfilled composites generally became darker, more chromatic, and more opaque. Since deterioration of the surface was not yet evident, these changes in color are attributed to the formation of colored degradation products.

As accelerated aging continued, deterioration of the surface of the composites occurred (Fig.). The extent of deterioration was greater for the conventional composites than for the microfilled composites. The surface deterioration of the conventional composites caused them to appear lighter and much less chromatic after extended aging compared to early aging. The color parameters of the microfilled composites were much less affected by surface deterioration after extended aging. Changes in color of the microfilled composites after extended aging are attributed to the continuing formation of colored degradation products.

\section{Conclusions.}

The color stability of seven commercial composite restorative materials under conditions of accelerated aging was evaluated by reflection spectrophotometry at baseline and 300,600 , and $900 \mathrm{~h}$. During early aging the composites generally became darker, more chromatic, and more opaque. Changes in color of the conventional composites during aging were influenced by erosion of the resin matrices and exposure of filler particles. Color stability of the microfilled composites

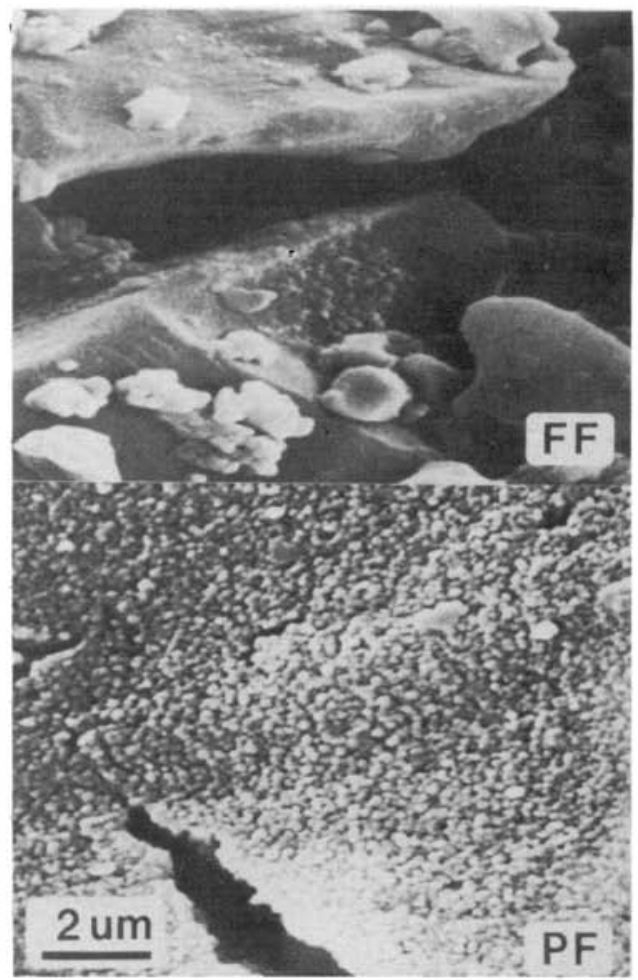

Fig. - Scanning electron photomicrograph of the surface of conventional composite (FF) and microfilled composite (PF) after $900 \mathrm{~h}$ of aging.

under the in vitro conditions tested was better than that of the conventional composites and did not appear to be influenced as much by erosion.

\section{REFERENCES}

1. POWERS, J.M.; DENNISON, J.B.; and KORAN, A.: Color Stability of Restorative Resins under Accelerated Aging, $J$ Dent Res 57: 964-970, 1978.

2. DENNISON, J.B.; CRAIG, R.G.; and BOZELL, R.R.: Clinical Evaluation of Class 4 Restorations for Color Stability, IADR Progr \& Abst 58:No. 328, 1979.

3. WYSZECKI, G. and STILES, W.S.: Color Science, New York: Wiley \& Sons, Inc., 1967, $628 \mathrm{pp}$.

4. Opacity of Paper, D589-65 1970: In ASTM Standards, part 20, Philadelphia: American Society for Testing and Materials, 1975, pp. 86-88.

5. A Manual of Elementary Statistics Using MIDAS, Ann Arbor: University of Michigan, Statistical Research Laboratory, 1975, 301 pp.

6. GUENTHER, W.C.: Analy sis of Variance, Englewood Cliffs, NJ: Prentice-Hall, 1964, 199 pp. 